\title{
Immunogenicity of a third scheduled dose of rotavirus vaccine in Australian Indigenous infants to improve protection against gastroenteritis: a phase IV, double-blind, randomised, placebo-controlled clinical trial
}

\begin{abstract}
Bianca F Middleton, Margie Danchin, Mark A Jones, Amanda J Leach, Nigel Cunliffe, Carl D Kirkwood, Jonathan Carapetis, Sarah Gallagher, Lea-Ann Kirkham, Caitlyn Granland, Monica McNeal, Julie A Marsh, Claire S Waddington, Thomas L Snelling.

Global and Tropical Health Division, Menzies School of Health Research, Charles Darwin University, Darwin Northern Territory, Australia (BF Middleton FRACP, S Gallagher BNurse); Vaccine Uptake Group, Murdoch Children's Research Institute, Parkville, Victoria, Australia (M Danchin PhD); Department of Paediatrics, University of Melbourne, Parkville, Victoria, Australia (M Danchin PhD); Department of General Medicine, Royal Children's Hospital (M Danchin PhD); Wesfarmers Centre of Vaccines and Infectious Diseases, Telethon Kids Institute, Perth, Western Australia, Australia (MA Jones MBiostat, Prof J Carapetis PhD, LA Kirkham PhD, C Granland BSc(hons), JA Marsh PhD, Prof TL Snelling, PhD); Child Health Division, Menzies School of Health Research, Charles Darwin University, Darwin, Northern Territory, Australia (Prof AJ Leach PhD); Clinical Infection, Microbiology and Immunology, University of Liverpool, Liverpool, UK (Prof N Cunliffe PhD); Enteric and Diarrheal Diseases, Bill and Melinda Gates Foundation, Seattle, Washington, USA (CD Kirkwood $\mathrm{PhD}$ ); Centre for Child Health Research, University of Western Australia, Perth, Western Australia, Australia (Prof J Carapetis, LA Kirkham PhD); Department of Pediatrics, University of Cincinnati College of Medicine, Cincinnati, Ohio (M McNeal MS); Division of Infectious Disease, Cincinnati Children's Hospital Medical Centre, Cincinnati, Ohio (M McNeal MS); Department of Medicine, University of Cambridge School of Clinical Medicine, Cambridge, UK (CS Waddington DPhil); School of Public Health, University of Sydney, New South Wales, Australia (MA Jones MBiostat, Prof TL Snelling PhD); School of Public Health, Curtin University, Western Australia (Prof TL Snelling PhD).
\end{abstract}

Correspondence to: Dr Bianca F Middleton, Global and Tropical Health Division, Menzies School of Health Research, Charles Darwin University, Darwin, Northern Territory, 0810, Australia bianca.middleton@ menzies.edu.au

\section{Research in context}

\section{Evidence before this study}

Rotavirus vaccine programs have reduced the global burden of gastroenteritis disease among young children, but rotavirus still causes $>200,000$ child deaths each year. A recent systematic review in the Lancet Global Health found that the effectiveness of oral rotavirus vaccines is variable, from $45-58 \%$ in settings with high child mortality to $83 \%-85 \%$ in settings with low child mortality. In high child mortality settings there is also evidence of waning effectiveness after 12 months old. Reduced vaccine effectiveness has also been reported among Australian Aboriginal children. Previous trials have failed to demonstrate improved rotavirus vaccine effectiveness with strategies such as withholding breastfeeding, or co-administering vaccines with probiotics or zinc. Pre-licensure studies of Rotarix in Africa did not clearly indicate whether a three-dose Rotarix schedule had benefit over a two-dose schedule, although all vaccine doses were given before infants were six months old when maternal antibodies may impede vaccine responses. Trials in Bangladesh and Mali found that a third Rotarix dose given after 6 months old improved the immune response to vaccine.

\section{Added value of this study}

In the first stage of our novel two-stage randomised clinical trial, we showed that scheduling an additional Rotarix dose for remote Australian Aboriginal infants after 6 months old increased the proportion with evidence of vaccine seroresponse.

\section{Implications of all the available evidence}

Scheduling an additional dose of Rotarix after 6 months old is feasible, and trials in three settings have now demonstrated that it improves immune responses. Trials should now be conducted in a number of high burden settings to determine whether this strategy results in improved clinical protection against sefore.tgastreprinteritits new research that has not been certified by peer review and should not be used to guide clinical practice. 
medRxiv preprint doi: https://doi.org/10.1101/2021.09.26.21264122; this version posted September $27,2021$. The copyright holder for this preprint (which was not certified by peer review) is the author/funder, who has granted medRxiv a license to display the preprint in It is made available under a CC-BY-ND 4.0 International license .

\section{Background}

The oral rotavirus vaccine, Rotarix (GlaxoSmithKline), is licensed for use in infants as two doses in the first six months of life. For infants living in settings with high child-mortality, and also for rural and remote Australian Aboriginal infants, clinical protection conferred by two doses of Rotarix appears to be reduced. We assessed the effect of an additional dose of Rotarix on vaccine immune responses among Aboriginal children who are 6 to $<12$ months old.

\section{Methods}

ORVAC is a two-stage, double-blind, randomised, placebo-controlled trial conducted across regional urban and remote locations of Australia's Northern Territory. Aboriginal children 6 to $<12$ months old who had received one or two prior doses of Rotarix were randomised 1:1 to receive an additional dose of Rotarix or matched placebo. The primary immunological endpoint was seroresponse defined as an anti-rotavirus $\operatorname{IgA}$ level $\geq 20 \mathrm{AU} / \mathrm{mL}$, approximately one month following Rotarix or placebo. ClinicalTrials.gov (NCT02941107).

\section{Findings}

Between March 2018 and August 2020, 253 infants were enrolled. Of these, 178 infants (70\%) had analysable serological results after follow-up; 89 randomised to Rotarix and 89 to placebo. The proportion with a seroresponse was $85 \%$ after Rotarix compared to $71 \%$ after placebo; the probability of a higher rate of seroresponse in the Rotarix than the placebo arm was $99 \%$. There were no occurrences of intussusception or any serious adverse events attributed to Rotarix or placebo in the 28 days following the additional dose of Rotarix or placebo.

\section{Interpretation}

An additional dose of Rotarix among Australian Aboriginal infants 6 to $<12$ months old increased the proportion with a vaccine seroresponse. If it can be proven that this translates into better protection against disease, scheduling an additional dose may be a viable strategy for further reducing the global burden of rotavirus disease.

\section{Funding}

NHMRC (GNT1086952). 
medRxiv preprint doi: https://doi.org/10.1101/2021.09.26.21264122; this version posted September $27,2021$. The copyright holder for this preprint (which was not certified by peer review) is the author/funder, who has granted medRxiv a license to display the preprint in

It is made available under a CC-BY-ND 4.0 International license .

\section{Introduction}

Before the introduction of vaccines, it was estimated that rotavirus was responsible for the deaths of more than 500000 young children every year, predominantly in low-resource settings. ${ }^{1}$ Since 2006, more than 100 countries have implemented rotavirus vaccines in their national immunisation programs, resulting in a substantial reduction in the number of gastroenteritis-related hospitalisations and deaths. ${ }^{2}$ However, rotavirus vaccine effectiveness is variable, being highest in settings with low child mortality (VE 83\% - 85\%), and lowest in settings with high child mortality (VE 45\%-58\%) where there is also evidence of waning effectiveness after 12 months old. ${ }^{3}$

In Australia, introduction of rotavirus vaccines was followed by a $71 \%$ decline in rotavirus hospitalisations in children < 5 years old. ${ }^{4}$ However, for 1-4 years old Aboriginal and Torres Strait Islander children (hereafter respectfully referred to as Aboriginal children), rotavirus hospitalisations fell by only $8 \%$ in the same period. ${ }^{4}$ Despite achieving over $70 \%$ vaccine coverage, rotavirus hospitalisations among Aboriginal children living in rural and remote central and northern Australia remained more than 20 times higher than for non-Aboriginal children living in other states and territories of Australia. ${ }^{4}$ During two separate G2P[4] genotype rotavirus epidemics in the Northern Territory, rotavirus vaccine effectiveness was estimated (albeit imprecisely) to be as low as $20 \%$ (OR $0 \cdot 81 ; 95 \%$ CI $0.32-2 \cdot 05$ and OR $0.79 ; 95 \%$ CI $0.46-1 \cdot 34$ ), with evidence of little or no protection after 12 months old. ${ }^{5,6}$

Controlled trials in Africa suggest that administering three rather than two doses of Rotarix might provide more sustained protection against severe rotavirus gastroenteritis in those settings. These studies observed a trend towards higher clinical efficacy in the second year of life with three-dose vs two-dose schedules, albeit with wide and overlapping confidence intervals. In South Africa, vaccine efficacy against severe rotavirus gastroenteritis in the second year of life was 3\% (95\% CI, $-43 \%$ to $82 \%$ ) in two-dose vaccinated children, and $76 \%$ (95\% CI, $-143 \%$ to $100 \%)$ in the three-dose group; ${ }^{7}$ in Malawi, vaccine efficacy in the second year of life was 3\% (95\% CI, $-101 \%$ to 53\%) in the two-dose group and $33 \%$ (95\% CI, $-47 \%$ to $71 \%$ ) in the three-dose group. ${ }^{8}$ However, each of these studies gave all vaccine doses in an accelerated schedule and before infants were six months old, when persisting maternally-derived anti-rotavirus IgG antibodies might diminish IgA vaccine responses. ${ }^{9}$

In Australia, Rotarix (GlaxoSmithKline, Belgium) oral rotavirus vaccine is administered in a two-dose schedule, with dose one scheduled at 2 months (6-14 weeks) old and dose two at 4 months (10-24 weeks) old. We hypothesised that for regional and remote Aboriginal infants, administering an additional Rotarix dose after 6 months old might improve their immune response and thereby extend protection against rotavirus gastroenteritis into the second year of life.

We designed a two-stage randomised controlled clinical trial to determine both the immunological effect (Stage 1) and clinical protection (Stage 2) of administering an additional dose of oral rotavirus vaccine to Northern Territory Aboriginal children 6 to $<12$ months old. Here we report the immunological results of Stage 1.

\section{Methods}

\section{Study design}

ORVAC is a two-stage, double-blind, randomised, placebo-controlled, Bayesian clinical trial evaluating the immunological and clinical effectiveness of administering an additional dose of Rotarix oral rotavirus vaccine to Aboriginal infants who are 6 to $<12$ months old. 
medRxiv preprint doi: https://doi.org/10.1101/2021.09.26.21264122; this version posted September 27,2021 . The copyright holder for this preprint (which was not certified by peer review) is the author/funder, who has granted medRxiv a license to display the preprint in

It is made available under a CC-BY-ND 4.0 International license .

ORVAC Stage 1 was conducted in regional urban and remote locations of the tropical north and arid centre of Australia's Northern Territory (NT). Remote areas of the NT encompass some of the most socially disadvantaged regions in Australia. ${ }^{10}$ There are approximately 3,600 infants born in the NT each year, approximately one-third of whom are Aboriginal. ${ }^{11}$

Both the study protocol and statistical analysis plan have been published. ${ }^{12,13}$ Approvals were obtained from the NT Department of Health and Menzies School of Health Research Human Research Ethics Committee (2016-2658), and the Central Australian Human Research Ethics Committee (16-426). The protocol is registered on ClinicalTrials.gov (NCT02941107).

\section{Participants}

Potentially eligible infants were identified after birth from participating hospitals and from client lists at remote community health centres. Written informed consent was obtained from the legally responsible caregiver of participating infants (hereafter 'parent'). In keeping with the policy-focussed objectives, all NT Aboriginal children aged 6 to $<12$ months old who had received one or two prior doses of Rotarix met the inclusion criteria for enrolment. Criteria for exclusion (contraindication to vaccine) and for deferred enrolment (acute diarrhoeal or systemic febrile illness, or receipt of Rotarix in the preceding 28 days) were based on national guidelines. ${ }^{14}$

\section{Randomisation and blinding}

Randomisation of eligible participants was undertaken by contiguous allocation from a computergenerated random sequence, within two strata (regional urban or remote) to receive either Rotarix or placebo in a ratio of 1:1. Rotarix is a human monovalent oral live-attenuated vaccine comprising a G1P[8] strain, the most common human disease-causing serotype worldwide. The placebo (produced by Optima Ovest, Australia) was a clear and flavoured solution used as a pharmaceutical excipient which, once prepared by an unblinded study nurse, was identical in appearance to the active vaccine product. Rotarix and placebo were drawn into identical syringes and delivered by oral administration.

\section{Procedures}

Following consent and eligibility assessment, a baseline blood sample of $1.2 \mathrm{~mL}$ was collected to measure anti-rotavirus serum $\operatorname{IgA}$ levels before administration of Rotarix or placebo, and a follow-up blood sample of $1 \cdot 2 \mathrm{~mL}$ was collected $28-55$ days afterwards.

Medical record and hospital admission review and/or attempted telephone contact of the guardians occurred between 14 and 21 days after administration of Rotarix or placebo to ascertain any adverse events.

Laboratory procedures for measuring serum IgA to rotavirus have been detailed previously. ${ }^{12,15,16}$ In brief, specific rotavirus IgA antibodies were measured by enzyme-linked immunoassays using rabbit anti-rotavirus polyclonal antisera as the coating antibody to capture a rotavirus lysate (G1P8) strain. Concentrations of rotavirus-specific $\operatorname{IgA}$ were measured in patient serum samples using a reference standard having been assigned a concentration of 1000 Arbitrary Units $(\mathrm{U}) / \mathrm{mL}$.

\section{Outcomes}

The primary immunological endpoint was vaccine seroresponse defined as serum anti-rotavirus IgA $\geq$ $20 \mathrm{AU} / \mathrm{mL}$ measured approximately one month (28-55 days) after Rotarix or placebo. The secondary immunological endpoint was the change in anti-rotavirus serum IgA titre one month ( 28 - 55 days) after the additional dose of Rotarix or placebo.

Safety endpoints were the occurrence of intussusception (fulfilling Brighton criteria ${ }^{17}$ ) or any serious adverse event within the first 28 days after administration of Rotarix or placebo. 
medRxiv preprint doi: https://doi.org/10.1101/2021.09.26.21264122; this version posted September 27, 2021. The copyright holder for this preprint (which was not certified by peer review) is the author/funder, who has granted medRxiv a license to display the preprint in It is made available under a CC-BY-ND 4.0 International license .

\section{Statistical methods}

All analyses occurred within a Bayesian inferential framework. Analysis of the immunological endpoint was undertaken as specified in the published statistical analysis plan. ${ }^{13}$

The study design and operating characteristics, including sample size, number and timing of interim analyses, power and false positive rate were calibrated via pre-study simulations. In brief, Stage 1 was designed to have $90 \%$ power to detect a differential increase in the proportion with IgA seroresponse of 0.05 in the placebo arm versus 0.15 in the Rotarix arm, with a maximum of 250 infants with immunologic results. In the null scenario (no increase in seroresponse), the risk of a false positive conclusion was estimated to be $1 \cdot 1 \%$.

As pre-specified in the protocol, the first scheduled analysis occurred after 70 infants had full immunogenicity results available and subsequent analyses occurred following the enrolment of every $50^{\text {th }}$ infant until 250 infants were enrolled. At each scheduled analysis we used a logistic regression model to estimate the log-odds of seroresponse by treatment group ( Rotarix versus the placebo). We used the posterior predictive distribution to evaluate pre-specified adaptation rules based on a decision threshold for expected success. We prespecified that enrolment into the immunogenicity study (Stage 1) would stop before 250 enrolments if the predicted probability of expected success was $>90 \%$ or that futility was evidence with $>85 \%$ probability. Pre-specified sensitivity analyses were performed, adjusting for locality and number of prior doses of Rotarix.

Analyses were implemented in R version 4.02 using Stan interfaced by RStan version $2 \cdot 21 \cdot 2$. The analyses and safety data were regularly reviewed by an independent Data Safety \& Monitoring Committee.

\section{Role of the funding source}

ORVAC Stage 1 was funded by the National Health and Medical Research Council (GNT1086952) which had no role in study design, data collection, data analysis, data interpretation, or writing of this report.

\section{Results}

Enrolment occurred between March 25, 2018 and August 28, 2020. The pre-specified criterion for early stopping of Stage 1 was not met at any scheduled analysis and a total of 253 infants were enrolled. Of these, $64(25 \%)$ were from regional urban centres (Darwin or Alice Springs) and the remaining 189 (75\%) resided in remote communities; 241 (95\%) were verified as having received two doses of Rotarix at least 28 days prior to enrolment. Of the first 250 infants enrolled, three were replaced: one declined baseline blood collection, one had multiple unsuccessful attempts at blood collection, and one infant moved interstate prior to follow-up and was withdrawn.

Of the 253 randomised infants, 128 were assigned to receive Rotarix and 125 to placebo; 120 and 121 respectively had analysable IgA results at baseline (Figure 1). The number with anti-rotavirus IgA concentration $\geq 20 \mathrm{IU} / \mathrm{mL}$ at baseline was 83 of $120(69 \%)$ in the Rotarix arm and 92 of $121(76 \%)$ in the placebo arm; the median baseline IgA concentration was $59 \cdot 6 \mathrm{IU} / \mathrm{mL}$ (Q1-Q3: 17.8-151.0) in the Rotarix group and 93.1 IU/mL (Q1-Q3: 21·2-164·0) in the placebo group (Table 1). 
medRxiv preprint doi: https://doi.org/10.1101/2021.09.26.21264122; this version posted September $27,2021$. The copyright holder for this preprint (which was not certified by peer review) is the author/funder, who has granted medRxiv a license to display the preprint in

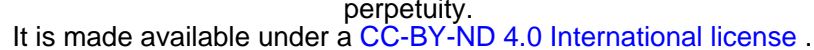

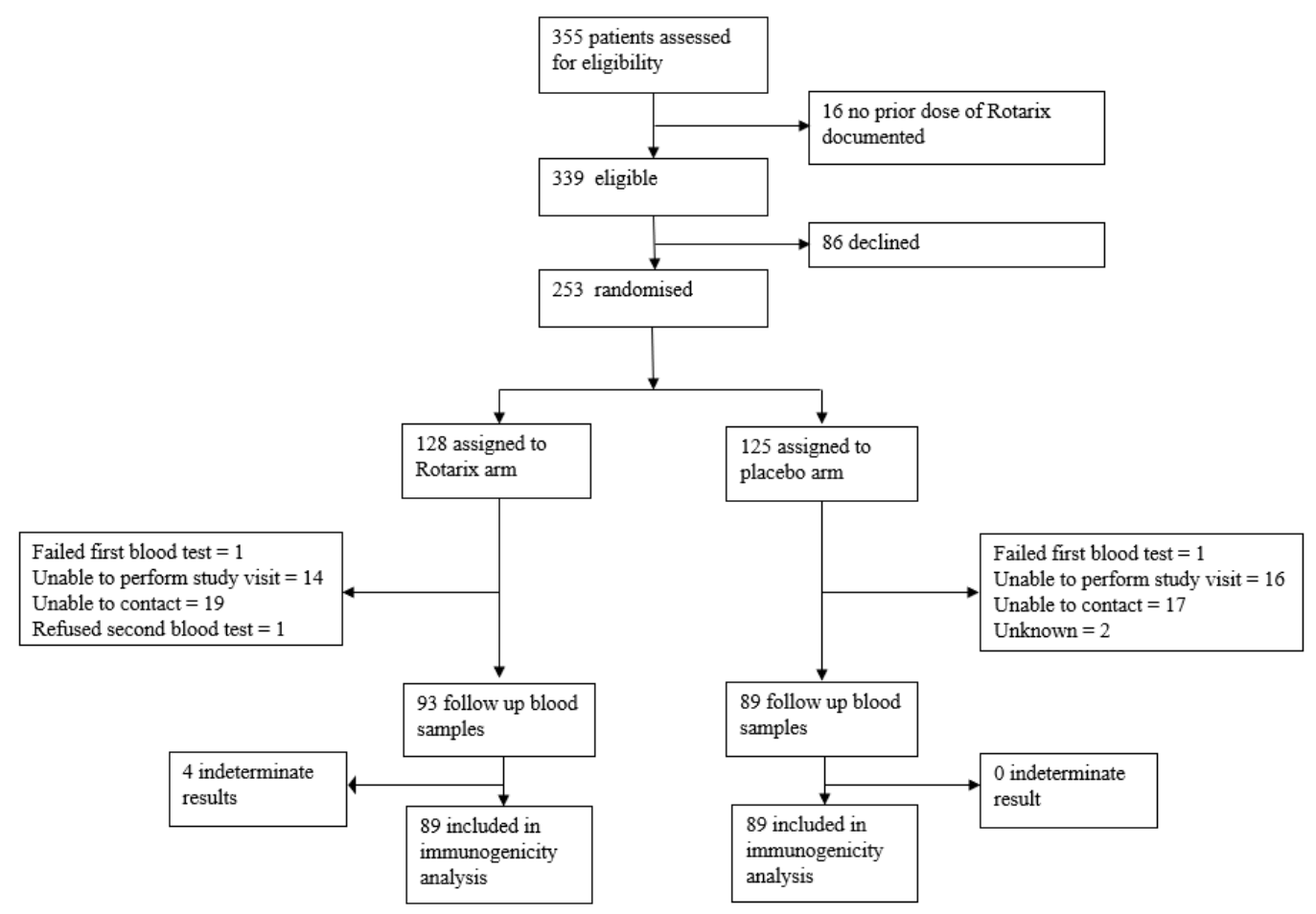

Figure 1: Trial profile - flow diagram of the progress of participants through ORVAC Stage 1.

\begin{tabular}{|c|c|c|}
\hline & Rotarix $(n=128)$ & Placebo $(n=125)$ \\
\hline \multicolumn{3}{|l|}{ Sex } \\
\hline Male & $64(50 \cdot 0 \%)$ & $67(53 \cdot 6 \%)$ \\
\hline Median Age (months; Q1-Q3) & $8 \cdot 5(6 \cdot 9-10 \cdot 3)$ & $8 \cdot 7(7 \cdot 3-10 \cdot 3)$ \\
\hline \multicolumn{3}{|l|}{ Indigenous Status } \\
\hline Aboriginal & $123(96 \cdot 1 \%)$ & $121(96 \cdot 8 \%)$ \\
\hline Torres Strait Islander & $5(3.9 \%)$ & $2(1.6 \%)$ \\
\hline Aboriginal and Torres Strait Islander & $0(0 \%)$ & $2(1.6 \%)$ \\
\hline \multicolumn{3}{|l|}{ Usual Location } \\
\hline Regional Urban & $31(24 \cdot 2 \%)$ & $33(26 \cdot 4 \%)$ \\
\hline Remote & $97(75 \cdot 8 \%)$ & $92(73 \cdot 6 \%)$ \\
\hline \multicolumn{3}{|l|}{ Breastfed } \\
\hline Exclusively & $10(7 \cdot 8 \%)$ & $8(6 \cdot 4 \%)$ \\
\hline Partially & $89(69.5 \%)$ & $97(77.6 \%)$ \\
\hline Not breastfed & $29(22.7 \%)$ & $20(16 \cdot 0 \%)$ \\
\hline Median Weight (kg; Q1-Q3) & $8.5(7.7-9.4)$ & $8 \cdot 5(7 \cdot 8-9 \cdot 1)$ \\
\hline Median Arm Circumference (mm; Q1-Q3) & $145(140-155)$ & $144(140-155)$ \\
\hline \multicolumn{3}{|l|}{ Prior Rotarix Doses } \\
\hline One & $9(7 \cdot 0 \%)$ & $3(2 \cdot 4 \%)$ \\
\hline Two & $119(93.0 \%)$ & $122(97 \cdot 6 \%)$ \\
\hline \multicolumn{3}{|l|}{ Seroresponse at Baseline } \\
\hline Yes & $83(64 \cdot 8 \%)$ & $92(73 \cdot 6 \%)$ \\
\hline No & $37(28.9 \%)$ & $29(23 \cdot 2 \%)$ \\
\hline Missing & $8(6 \cdot 2 \%)$ & $4(3 \cdot 2 \%)$ \\
\hline \multicolumn{3}{|l|}{ IgA Concentration at Baseline } \\
\hline Median (IU/mL; Q1-Q3) & $59 \cdot 6(17 \cdot 8-151 \cdot 0)$ & $93 \cdot 1(21 \cdot 2-164 \cdot 0)$ \\
\hline
\end{tabular}

Table 1: Baseline demographic characteristics, prior vaccine doses and seropositivity for the randomised population 
medRxiv preprint doi: https://doi.org/10.1101/2021.09.26.21264122; this version posted September $27,2021$. The copyright holder for this preprint (which was not certified by peer review) is the author/funder, who has granted medRxiv a license to display the preprint in

It is made available under a CC-BY-ND 4.0 International license .

Of the 253 infants randomised, 178 (70\%) were successfully followed up after one month and had analysable immunologic results; 89 in the Rotarix arm and 89 in the placebo arm. In the Rotarix arm, 76 of $89(85 \%)$ had evidence of vaccine seroresponse (serum $\mathrm{IgA} \geq 20 \mathrm{IU} / \mathrm{mL}$ ) one month afterwards. In the placebo arm, 63 of 89 (71\%) had evidence of vaccine seroresponse one month afterwards. The median IgA concentration was 157.1 AU/mL (Q1-Q3: 43.5-273.3) in the Rotarix arm and 76.9 AU/mL (Q1-Q3: 17.1-161·8) in the placebo arm (Figure 2); the geometric mean concentrations were 118.0 $\mathrm{AU} / \mathrm{mL}$ and $57.6 \mathrm{AU} / \mathrm{mL}$ in the Rotarix and placebo arms respectively.

The odds ratio of seroresponse at follow-up in the Rotarix versus the placebo arm was 2.5 (95\% credible interval: $1 \cdot 1$ to $5 \cdot 0$ ) with a $99 \%$ probability of a higher proportion with seroresponse in the Rotarix than in the placebo arm. The odds ratios of seroresponse were similar after adjusting for baseline differences in remoteness $(2.44 ; 95 \% \mathrm{CrI}: 1.09$ to 4.85$)$ and number of prior Rotarix doses $(2.48 ; 95 \%$ CrI: 1.09 to 4.92).

Neither of the pre-specified stopping rules were met at the nominate decision threshold. However, at the final stage 1 analysis, the predicted probability of expected success with complete data was $89 \%$.

In the period between randomisation and 28 days afterwards, there were three serious adverse events (hospitalisation for pneumonia, bronchiolitis and salmonella enteritis); none were attributed to Rotarix/placebo and there were no cases of intussusception or death. The treatment assignment of infants remains concealed to allow blinded follow-up of their clinical outcomes, with safety outcomes to be reported by study arm at the completion of ORVAC Stage 2 .
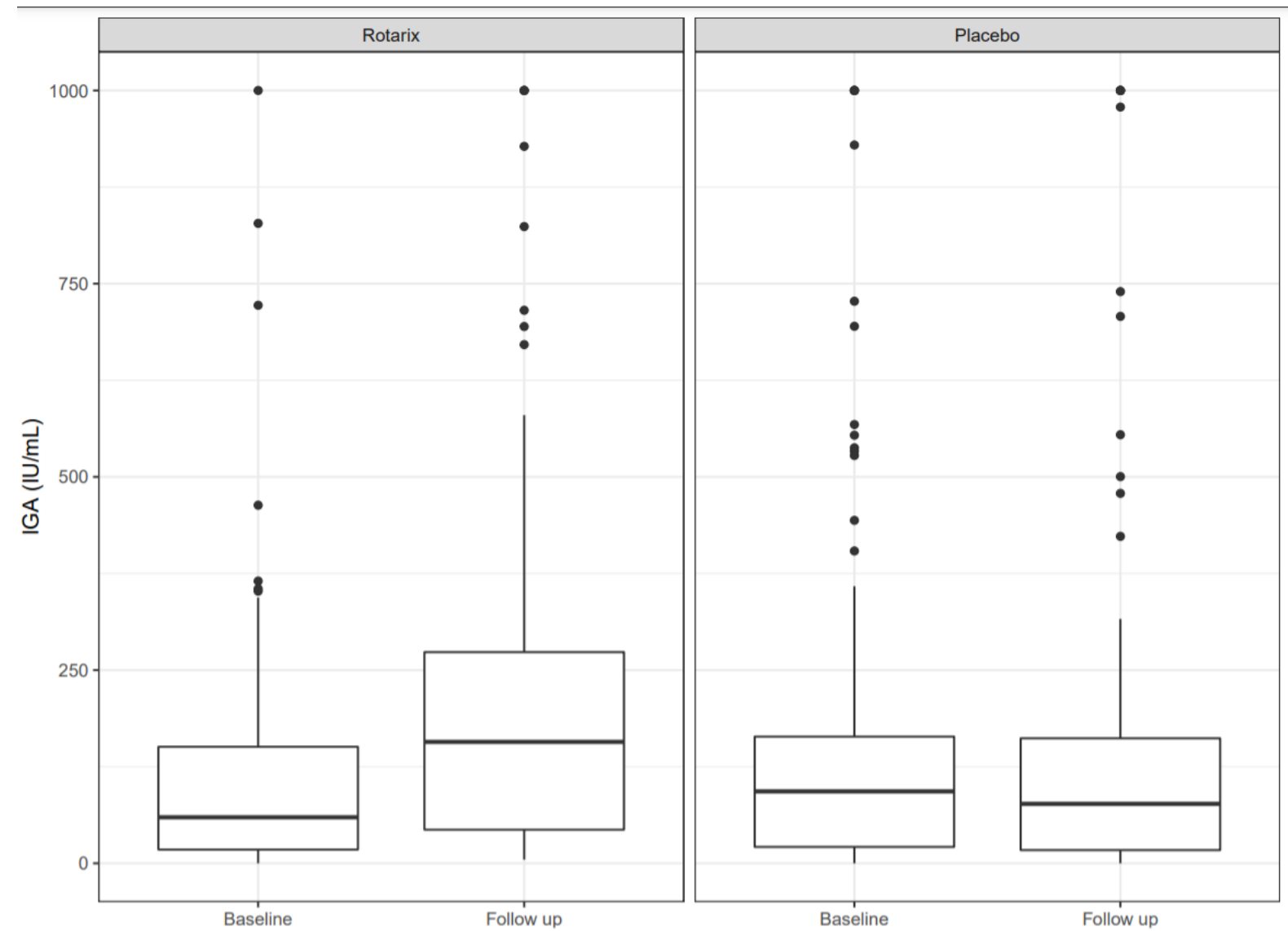

Figure 2: Change in anti-rotavirus IgA tire (AU/ml) from baseline to 28 - 56 days following the additional dose of Rotarix/ placebo. 
medRxiv preprint doi: https://doi.org/10.1101/2021.09.26.21264122; this version posted September $27,2021$. The copyright holder for this preprint (which was not certified by peer review) is the author/funder, who has granted medRxiv a license to display the preprint in

It is made available under a CC-BY-ND 4.0 International license.

\section{Discussion}

Administering an additional dose of Rotarix vaccine at 6 to $<12$ months old increased the proportion of Aboriginal infants with evidence of anti-rotavirus IgA seroresponse by $16 \%$ (from $69 \%$ to $85 \%$ ). There was no increase in seroresponse among placebo recipients, demonstrating that the increase in anti-rotavirus serum IgA observed in Rotarix recipients is unlikely to be attributable to natural infection. ORVAC was purposely pragmatic, being conducted under real-world conditions and with exclusion criteria largely limited to medical contraindications to vaccination. Three quarters of enrolled infants resided in remote locations.

These results are consistent with evidence from trials in Bangladesh and Mali where rotavirus vaccines were co-administered with measles-rubella vaccine at 9 months and with measles, yellow fever and meningococcal vaccines at 9-11 months, respectively. In the former trial, anti-rotavirus IgA seroresponses increased from $45 \%$ to $75 \%$ following an additional dose of RotaTeq rotavirus vaccine ${ }^{18}$ and in the latter trial anti-rotavirus IgA seroresponse increased from $53 \%$ to $70 \%$ following an additional dose of Rotarix. ${ }^{19}$ Taken together, these data suggest that scheduling an additional Rotarix dose after 6 months old is likely to have an appreciable effect on seroresponse rates across a range of high burden settings.

Reduced vaccine protection has been described for a number of oral vaccines in low-and middle-income settings, ${ }^{20}$ but the reasons are not well understood. For oral rotavirus vaccines, several possible factors have been proposed including high levels of maternal-derived vaccine neutralising anti-rotavirus antibodies, poor nutrition, intestinal microbiota dysbiosis and environmental enteropathy, high prevalence of comorbid infections, and prevalent genetic determinants of poor vaccine responses or increased susceptibility to different rotavirus genotypes. ${ }^{21}$ Under 5 mortality is several-fold higher among remote Australian Aboriginal infants than among non-Aboriginal infants, ${ }^{22}$ but is low compared to most low- and middle- income settings. While environmental enteropathy, food insecurity and iron deficiency affect many remote Aboriginal children, ${ }^{23}$ the mid-upper arm circumference of participants in our study suggest protein-calorie malnutrition was not prevalent.

The mechanism of immunological protection against rotavirus infection and immune responses to vaccination remain incompletely understood, but likely involve both humoral and cellular mechanisms. ${ }^{24}$ Anti-rotavirus serum IgA is widely used as an immunological correlate of clinical protection at the population level; ${ }^{25}$ lower anti-rotavirus IgA seroresponses to rotavirus vaccines are observed in settings where reduced clinical protection against rotavirus disease is also observed. A systematic review reported rates of IgA seroresponse to rotavirus vaccine corresponded with a country's child mortality rate, $53 \%$ (95\% CI, $41-64 \%$ ) in countries with high under-5 mortality rate compared to $74 \%$ (95\% CI, 61-84\%) in countries with medium under-5 mortality rate and 87\% (95\% CI, 78-925) in countries with low under-5 mortality rate. ${ }^{26}$ Similarly, post-immunisation anti-rotavirus IgA geometric mean concentration $(\mathrm{GMC})<90 \mathrm{IU} / \mathrm{mL}$ at a population level has been correlated with reduced vaccine efficacy in that population. ${ }^{26}$ In our study, an additional dose of Rotarix vaccine increased the probability of seroresponse from $71 \%$ to $85 \%$, and the geometric mean concentration of anti-rotavirus IgA from $58 \mathrm{AU} / \mathrm{mL}$ to $118 \mathrm{AU} / \mathrm{mL}$.

While high serum anti-rotavirus IgA vaccine seroresponse has been correlated with high population efficacy of oral rotavirus vaccines, it is not a perfect serological correlate of protection; ${ }^{24}$ it is therefore important to evaluate whether the improved anti-rotavirus seroresponses observed in this study translate into improved real-world clinical protection against rotavirus disease. ORVAC is designed as a Bayesian seamless two-stage vaccine clinical trial, in which extension to enable evaluation of clinical protection (Stage 2) is predicated on first demonstrating an acceptable vaccine immune response (Stage 1). Subject to resourcing, ORVAC Stage 2 plans to enrol up to 750 additional infants to determine if 
medRxiv preprint doi: https://doi.org/10.1101/2021.09.26.21264122; this version posted September $27,2021$. The copyright holder for this preprint (which was not certified by peer review) is the author/funder, who has granted medRxiv a license to display the preprint in

It is made available under a CC-BY-ND 4.0 International license .

scheduling an additional dose of Rotarix vaccine at 6 to $<12$ months old results in improved protection against acute gastroenteritis/diarrhoea illness up to 3 years old.

Rotashield, a rhesus-derived rotavirus vaccine licensed in the 1990s caused intussusception in a small number of infants after their first dose of vaccine, with the highest risk in infants receiving their first dose after 3 months old. ${ }^{27}$ As a consequence, current rotavirus vaccines were tested and licensed for use in early infancy only, although post-licensure studies have found no increase in risk of intussusception ${ }^{28}$ and the World Health Organization advises that children in high burden settings may receive rotavirus vaccine up to age 24 months old. ${ }^{27}$ The baseline incidence of intussusception among NT Aboriginal children is 16 per 100,000 live births which is several fold lower than the baseline rate in other Australian children. ${ }^{29}$ We found no cases of intussusception in our study, although an increased risk could not be excluded. In Australia, Rotarix is not recommended after 24 weeks old in line with its licensure. Most infants (> 95\%) enrolled in our study had received two Rotarix doses prior to enrolment, but delayed and incomplete rotavirus vaccination has been reported previously among Aboriginal children. ${ }^{30}$ Relaxing the upper age limit for Rotarix vaccination might not only allow for additional vaccine doses, it might also improve two-dose vaccine coverage by increasing opportunity for receipt of missed doses.

Randomisation was used to ensure exchangeability of those in the Rotarix and placebo arms. The two arms were well-matched on most baseline factors, except those in the Rotarix arm were less likely than those in the placebo arm to be breastfed and were less likely to have evidence of a seroresponse at baseline (69\% vs 76\%). Almost one-third of infants (29\%) in our study could not contribute follow-up specimens to the immunological analysis. This was largely due to restrictions on travel by study staff to remote communities as a result of dangerous weather (monsoonal storms), cultural grieving ('sorry business') and restrictions imposed by jurisdictional and institutional authorities to prevent COVID-19 transmission. The proportion of Rotarix and placebo recipients with missing outcome data was similar, and while blinding ensures selection bias is unlikely, it is possible that rates of seroresponse were different in those with missing immunological outcome data.

Adaptive designs are increasingly used for pre-licensure therapeutic trials and may also have value in vaccine trials, especially in low-resource settings. ${ }^{31,32}$ Adaptive designs require upfront investment of resources into statistical modelling and simulations, ${ }^{32}$ but they might enable more judicious investment of field resources for recruitment and follow-up, and may expedite translation of positive trial findings into clinical practice, or re-focussing on alternative strategies if trial results are negative. Additionally, when superiority or futility of an intervention is already clear, the ability to stop trials early is ethical because it minimises the burden and risks of study participation; ${ }^{31}$ these were motivating factors in the design choice for ORVAC in this vulnerable and highly researched population.

\section{Conclusions}

Administration of an additional dose of Rotarix vaccine to 6 to $<12$ months old Australian Aboriginal children increased the proportion of children with evidence of a vaccine seroresponse by approximately $16 \%$. If it can be demonstrated that this translates into improved protection against gastroenteritis this could be a highly viable strategy to further decrease the burden of diarrhoeal disease among young children in this and other high-burden settings. 
medRxiv preprint doi: https://doi.org/10.1101/2021.09.26.21264122; this version posted September $27,2021$. The copyright holder for this preprint (which was not certified by peer review) is the author/funder, who has granted medRxiv a license to display the preprint in

It is made available under a CC-BY-ND 4.0 International license .

\section{Contributors}

BFM wrote the first draft of the report with input from TLS. BFM and TLS developed the study processes and procedures and primarily authored the initial trial protocol. TLS and CSW conceived the study and JAM and MAJ devised the Bayesian approach. CSW, CDK, MD, NC, JC and AJL contributed to the clinical aspects of the protocol. MD, SG and JAM contributed to the study design. MM was responsible for establishing the assay and LAK and CMG were responsible for analysis of the serum samples. MAJ was responsible for statistical analysis, which was verified by JAM. All authors had full access to all the data in the study, contributed to the manuscript and had final responsibility for the decision to submit for publication. All authors meet the requirements for authorship inclusion and have seen and approved the final version of this manuscript

\section{Declaration of interests}

NC declares that his employer, University of Liverpool, has received grant funding for rotavirus research from GlaxoSmithKline, the manufacturer of Rotarix. We declare no other competing interests.

\section{Data sharing}

At the completion of follow-up, analysis and reporting of ORVAC Stage 2, deidentified data collected for the study, including individual participant data and a data dictionary defining each field in the set, will be made available to others on request to the corresponding author, subject to a signed data access agreement and any necessary ethics approvals. The study protocol and statistical analysis plan are published.

\section{Acknowledgments}

This work was supported by the National Health Medical Research Council (NHMRC) (1086952). BFM is supported by an NHMRC Postgraduate Scholarship (1134095), a RACP P\&CHD NHMRC Scholarship and a Douglas and Lola Douglas Scholarship in Medical Science, Australian Academy of Science. TS was supported by an NHMRC Career Development Fellowship (1111657). MD is supported by an MCRI Clinician Scientist Research Fellowship, University of Melbourne.

Nigel Cunliffe is affiliated to the National Institute for Health Research (NIHR) Health Protection Research Unit in Gastrointestinal Infections at University of Liverpool, in partnership with Public Health England, in collaboration with University of Warwick. Nigel Cunliffe is based at The University of Liverpool. The views expressed are those of the author(s) and not necessarily those of the NIHR, the Department of Health and Social Care or Public Health England.

The study investigators would like to acknowledge the valuable contribution of Aboriginal Elder, Ms Ada Parry, Aboriginal Members of the Steering Committee Dr Dennis Bonney, Dr Olivia O’Donoghue and Dr Simone Raye, and the Menzies School of Health Research Child Health Indigenous Reference Group. We would also like to acknowledge the valuable contribution of the independent Data Safety Monitoring Committee.

The authors acknowledge Professor Ross Andrews' contribution the design and implementation of the ORVAC trial. We would also like to sincerely thank Dr Monica McNeal and her team at Cincinnati Children's Hospital, USA for enabling training in the rotavirus IgA ELISA and their generous sharing of specialist reagents. This permitted the collected blood samples to remain on country in Australia, fulfilling the request from the local Child Health Indigenous Reference Group.

\section{References}

1. Parashar UD, Burton A, Lanata $\mathrm{C}$ et al. Global mortality associated with rotavirus disease among children in 2004. J Infect Dis 2009; 200 Suppl 1: S9-S15.

2. Burnett E, Parashar UD, Tate JE. Global impact of rotavirus vaccination on diarrhea hospitalizations and deaths among children <5 years old: 20062019. J Infect Dis 2020; 222(10): 1731 - 1739.

3. Burnett E, Parashar UD, and Tate JE. Real-world effectiveness of rotavirus vaccines, 2006-19: a literature review and meta-analysis. Lancet Glob Health 2020; 8(9): e1195-e1202.

4. Dey A, Wang H, Menzies R, Macartney K. Changes in hospitalisations for acute gastroenteritis in Australia after the national rotavirus vaccination program. Med J Aust 2012; 197(8): 453-7.

5. Snelling TL, Andrews RM, Kirkwood CD, Culvenor S, Carapetis JR. Case-control evaluation of the effectiveness of the G1P[8] human rotavirus vaccine during an outbreak of rotavirus G2P[4] infection in central Australia. Clin Infect Dis 2011; 52(2): 191-9. 
medRxiv preprint doi: https://doi.org/10.1101/2021.09.26.21264122; this version posted September $27,2021$. The copyright holder for this preprint (which was not certified by peer review) is the author/funder, who has granted medRxiv a license to display the preprint in It is made available under a CC-BY-ND 4.0 International license .

6. Middleton BF, Danchin M, Quinn H et al. Retrospective Case-Control Study of 2017 G2P[4] Rotavirus Epidemic in Rural and Remote Australia. Pathogens 2020; 9(10): 790.

7. Madhi SA, Kirsten M, Louw C et al. Efficacy and immunogenicity of two or three dose rotavirus-vaccine regimen in South African children over two consecutive rotavirus-seasons: a randomized, double-blind, placebo-controlled trial. Vaccine 2012; 30 Suppl 1: A44-51.

8. Cunliffe NA, Witte D, Ngwira BM et al. Efficacy of human rotavirus vaccine against severe gastroenteritis in Malawian children in the first two years of life: a randomized, double-blind, placebo controlled trial. Vaccine 2012; 30 Suppl 1: A36-43.

9. Moon SS, Groome MJ, Velasquez DE et al. Prevaccination Rotavirus Serum IgG and IgA Are Associated With Lower Immunogenicity of Live, Oral Human Rotavirus Vaccine in South African Infants. Clin Infect Dis 2016; 62(2): 157-65.

10. Zhao Y, You J, Wright J, Guthridge SL, Lee AH.Health inequity in the Northern Territory, Australia. Int J Equity Health 2013; 12: 79.

11. Australian Bureau of Statistics. Births, Australia $2019 . \quad 2020$. https://www.abs.gov.au/statistics/people/population/births-australia/latest-release (accessed August 18, 2021).

12. Middleton BF, Jones MA, Waddington CS et al. The ORVAC trial protocol: a phase IV, double-blind, randomised, placebo-controlled clinical trial of a third scheduled dose of Rotarix rotavirus vaccine in Australian Indigenous infants to improve protection against gastroenteritis. BMJ Open 2019; 9(11).

13. Jones MA, Graves T, Middleton B, Totterdell J, Snelling TL, Marsh JA. The ORVAC trial: a phase IV, doubleblind, randomised, placebo-controlled clinical trial of a third scheduled dose of Rotarix rotavirus vaccine in Australian Indigenous infants to improve protection against gastroenteritis: a statistical analysis plan. Trials 2020; $21(1): 741$.

14. Australian Technical Advisory Group on Immunisation (ATAGI). Australian Immunisation Handbook. Canberra: Australian Govenrment Department of Health, 2018.

15. Ward RL, Bernstein DI, Shukla R et al. Protection of adults rechallenged with a human rotavirus. J Infect Dis 1990; 161(3): 440-5.

16. Bernstein DI, Smith VE, Sherwood JR et al. Safety and immunogenicity of live, attenuated human rotavirus vaccine 89-12. Vaccine 1998; 16(4): 381-7.

17. Bines JE, Kohl KS, Forster J et al. Acute intussusception in infants and children as an adverse event following immunization: case definition and guidelines of data collection, analysis, and presentation. Vaccine 2004; 22(56): 569-74.

18. Haidara FC, Tapia MD, Sow SO et al. Evaluation of a Booster Dose of Pentavalent Rotavirus Vaccine Coadministered With Measles, Yellow Fever, and Meningitis A Vaccines in 9-Month-Old Malian Infants. J Infect Dis 2018; 218(4): 606-613.

19. Zaman K, Fleming JA, Victor JC et al. Noninterference of Rotavirus Vaccine With Measles-Rubella Vaccine at 9 Months of Age and Improvements in Antirotavirus Immunity: a Randomized Trial. Journal of infectious diseases 2016; 213(11): 1686-1693.

20. Parker EP, Ramani S, Lopman BA et al. Causes of impaired oral vaccine efficacy in developing countries. Future Microbiol 2018; 13: 97-118.

21. Velasquez DE, Parashar U, Jiang B. Decreased performance of live attenuated, oral rotavirus vaccines in lowincome settings: causes and contributing factors. Expert Rev Vaccines 2018; 17(2): 145-161.

22. Australian Institute of Health and Welfare. Australia's health 2018. Australia's health series no. 16. AUS 221. Canberra: AIHW, 2018.

23. Tonkin E, Kennedy D, Hanieh S et al. Dietary intake of Aboriginal Australian children aged 6-36 months in a remote community: a cross-sectional study. Nutr J 2020. 19(1): 34.

24. Clarke E, Desselberger U. Correlates of protection against human rotavirus disease and the factors influencing protection in low-income settings. Mucosal Immunol 2015. 8(1): 1-17.

25. Cheuvart B, Neuzil KM, Steele AD et al. Association of serum anti-rotavirus immunoglobulin A antibody seropositivity and protection against severe rotavirus gastroenteritis: analysis of clinical trials of human rotavirus vaccine. Hum Vaccin Immunother 2014. 10(2): 505-11.

26. Patel M, Glass RI, Jiang B, Santosham M, Lopman B, Parashar U. A systematic review of anti-rotavirus serum IgA antibody titer as a potential correlate of rotavirus vaccine efficacy. J Infect Dis 2013. 208(2): $284-94$.

27. World Health Organisation. Rotavirus vaccines WHO position paper: January 2013 - Recommendations. Vaccine. 2013. 31(52): 6170-1.

28. Lu HL, Ding Y, Goyal H, Xu HG. Association Between Rotavirus Vaccination and Risk of Intussusception Among Neonates and Infants: A Systematic Review and Meta-analysis. JAMA Netw Open 2019. 2(10): e1912458.

29. Webby RJ, Bines JE, Barnes GL, Tindall H, Krause V, Patel M. Intussusception in the Northern Territory: the incidence is low in Aboriginal and Torres Strait Islander children. J Paediatr Child Health 2006. 42(5): 2359; discussion 227-8. 
medRxiv preprint doi: https://doi.org/10.1101/2021.09.26.21264122; this version posted September 27, 2021. The copyright holder for this preprint (which was not certified by peer review) is the author/funder, who has granted medRxiv a license to display the preprint in

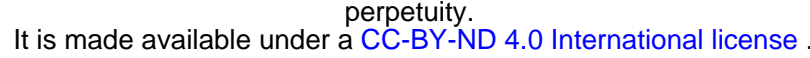

30. Moore HC, Fathima P, Gidding HF et al. Assessment of on-time vaccination coverage in population subgroups: A record linkage cohort study. Vaccine 2018. 36(28): 4062-4069.

31. Park JJH, Ford N, Xavier D et al., Randomised trials at the level of the individual. Lancet Glob Health 2021. 9(5): e691-e700.

32. Liu M, Li Q, Lin J, Lin Y, Hoffman E. Innovative trial designs and analyses for vaccine clinical development. Contemp Clin Trials 2021. 100: 106225. 